\title{
TRADITIONAL GAMES TO REINFORCE THE KNOWLEDGE LEARNED IN AN ENGINEERING MASTER DEGREE
}

\author{
Raquel Sanchis, Beatriz Andrés, Raúl Poler \\ Research Centre on Production Management and Engineering (CIGIP), \\ Universitat Politècnica de València (SPAIN)
}

\begin{abstract}
As long as human beings can remember, games have been conceived in order to get fun and as pastime for the free time. With the quick and significant advance of the Information and Communication Technologies (ICTs), these traditional games have been relegated to the background. These games, that several years ago were very well-known among students, currently are not popular anymore. University students are more focused on mobile apps and digital games rather than these out-of-date games. As students are unfamiliar with these traditional games, teachers have recovered them in order to be applied at master degree level with the main objective of "learning while playing". The traditional games implemented in the master degree classes are the hangman wordguessing and crossword games. There are different online tools that offer the possibility to configure customized hangman and crossword games in order to be adapted to the different subjects and lessons. Both games are performed in an Engineering Master Degree, more particularly in the subject of "Demand and Supply Management".
\end{abstract}

After performing both games in different sessions, the students' assessment is very positive and it seems that this kind of practice reinforces the students' knowledge gained through the master classes. The paper shows how these two games are applied at the university covering the examples used in the master degree and how these activities strengthen students' knowledge.

Keywords: Traditional Games, Engineering Master Degree, Learning while Playing, Hangman WordGuessing, Crossword.

\section{INTRODUCTION}

Instructional environments should be interactive, provide ongoing feedback, grab and sustain attention, and have appropriate and adaptive levels of challenge [1]. Therefore, it is of utmost importance to develop, during the instructional sessions, mechanisms that promote and reinforce the knowledge acquired. The mechanism developed and used for achieving this purpose should be challenging but also self-motivating. All these characteristics could be found in the learning games.

Learning games are activity structures in which players use a body of knowledge or set of skills as resources in their competition with other players [2]. Games are designed to generate a positive effect in players and are most successful and engaging when they facilitate the flow experience [3]. Flow state is a state of total absorption or engagement in an activity and refers to the optimal experience [4]. During the time that last the optimal experience, the payer is in a psychological state where this person is so immersed with the game that nothing else seems to matter. Past lines of research has shown that the flow state has positive impact on learning [5].

Moreover, games should also provide feedback to the students about their actual knowledge condition of a specific topic. According to [6] through the utilization of games in class, the students are selfjudged, since games remove teachers from the role of judge and free them to coach the activity rather than focus on evaluating it. Then, games have twofold objectives: (i) to reinforce the knowledge acquired but also (ii) to self-assess the level of knowledge acquired.

Almost everybody knows how to play Sudoku, Word Search, Hangman Wordguessing, Crossword... games, as they were very popular in the last decades because most of the newspapers usually dedicate one or two pages in their publications to these puzzles. However, currently they have lost popularity among young generations as these new generations are more focused on digital and mobile applications.

When a literature review is performed with some keywords, such as: learning games or traditional games for learning, most of the results obtained contain in the titles of the publications words such as 
video games, computer-based games, simulation games, mobile applications... among other but it is difficult to find current literature focused on traditional games for learning.

Moreover, it is always though that the traditional games, as the ones aforementioned, are usually used for learning in basic levels of education such as the primary school, or even in the high school but it is strange to find this kind of practices at the university.

Therefore, the objective of this paper is to offer a different view about how games can be used without the requirement of high technological skills to reinforce the knowledge of university students. However, it is worth to mention that although the traditional games could be applied without the use of any digital device and without utilizing any application to develop them, the Internet offers different alternatives, such as to create and configure a traditional game to be played online or the same option but using the game defined, in an offline way, for example printing and giving it to the students.

The paper is organized as follows. Section 2 offers a general description of what are both games about. Section 3 shows a summary of the free online resources and tools to design, configure and in most of the cases, also play to both games. Section 3 exposes the real experience gained through the use of the crossword and the hangman game during an educational session in an Engineering Master Degree. The education context is also defined is this section and it also offers both examples used at class. Finally, the section conclusions offer an overview of the main achievements and feelings.

\section{TRADITIONAL GAMES}

There are several traditional games all over the world. Some are specific of some countries, others are similar among countries but they have particular characteristics depending on the region where they are played and finally, most of them are universal. This paper is focused on two traditional games very well recognized by most of the students such as: the hangman wordguessing and crossword. Although they are familiar with these games, few are the students, who recognize that they have played.

The crossword game consists of a matrix of squares numbered that should be filled in with words defined thanks to the information provided through some statements (questions and/or definitions). The game gives to the players two kinds of information: (i) the information about the word that players have to find out but also (ii) the length of the words since player have available the matrix shape and the squares that composed the matrix. As the grid is composed by several squares interconnected, if the player starts to define a word, part of this word (some letters) will be the clue for defining another one. Therefore, as in the previous case, this game also becomes easier to be solved as the grid is filled in. The main challenge is figuring out how to integrate the list of words together within the grid so that all intersections of words are valid.

On the other hand, the usual version of the hangman game consists of one player (player 1) thinking a word, and the other player (player 2) trying to guess the word by suggesting letters, within a certain number of guesses that are determined by drawing how the body of a man is hung. The player ( 1 and 2 ) could be only on person but could also be a group of people. The player 1 wins if the full body is hanged while player 2 wins the game if he/she guesses the word before the man is hung. As player 2 is guessing letters, the game becomes easier because it is simpler to figure out the word. This is a game that does not require any type of technology nor costly devices to be played.

This second game is more competitive than the first one because it involves two players and the first one, only involves one, the player against the game. However, it could be easily transformed to a competitive game if all the players (for example the different students of a class) have to solve the same crossword but apart from this, the first student solving it correctly, will be the winner. In this case, the main aim is not only focused on finding out the different words properly but having a quick response in order to promote the rapid thinking too.

\section{ONLINE RESOURCES TO CUSTOMIZE THE TRADITIONAL GAMES}

As aforementioned, these games could be designed by hand because they are very effortless. The difficulty to design a crossword game is a little bit higher than in the case of the hangman game because the designer of the game has configure the matrix and locate the words, across and down, making them interconnected. In order to facilitate the design process of a crossword there are several online resources that allow and easy and quick way to define crosswords. Table 1 shows an overview of the main tools and some its characteristics to configure crosswords. 
Table 1. Tools to configure crossword games.

\begin{tabular}{|l|c|c|c|}
\hline Name & $\begin{array}{c}\text { Words } \\
\text { Limits }\end{array}$ & Printable & Fill in online \\
\hline The Teacher Corner [7] & 30 & Yes & Yes \\
\hline Instant Online Crossword Puzzle Maker [8] & - & No & Yes \\
\hline Crossword Labs [9] & - & $\begin{array}{c}\text { No } \\
\text { (As it is not offered } \\
\text { the empty option of } \\
\text { the crossword) }\end{array}$ & No \\
\hline Puzzle Maker [10] & - & Yes & No \\
\hline Teacher Stuff [11] & - & Yes & No \\
\hline Crossword Puzzles Games [12] & 20 & Yes & No \\
\hline Ed Helper [13] & 50 & Yes & No \\
\hline Eclipse Cross Word [14] & - & Yes & No \\
\hline
\end{tabular}

Most of the online resources have different options to configure crosswords, such as definition of the difficulty (not based on the words definition that is done by the user but on the structure and words allocation), colors, type of font, title of the crossword, etc. All the options shown in Table 1 are free, although the Ed Heler needs a subscription. Most of them do not have words limits, however there are other that present constrains with regard to the number of words and clues that could be defined when configuring the crossword.

Most of them also offer the possibility to print the crossword directly from the web browser or to download a file (pdf and/or image) with the crossword and the clues. Moreover, there are online resources that not only allow to define crosswords but they also offer the possibility to fill in the crossword online. In this case, only 2 tools from the 8 analyzed have this feature. There is one of the resources, particularly the Eclipse Cross Word, that it is not an online tool, but it is available online through downloading a .exe file and installing it in the computer.

All these tools facilitate the configuration process of a crossword making this process easier and quicker. The choice of one or another online tool depends on the characteristics of the crossword to be designed, although generally speaking, all the presented tools offer similar features.

On the other hand, there are also online tools that facilitate the definition and creation of hangman games. In most of them, the words have to be defined and during the game, it is shown the alphabet with the letters that the players have already used. Moreover, each time that the player does not guess a correct letter, the tool automatically draws a part of the body of a hangman. Some of these tools could be found in: ProProfs Brain Games [15], Ahorcado [16], MyLanguageExchange [17], AHangman [18], ...

Some of the games present the possibility to design the hangman game in different languages because they have in their libraries different alphabets. The choice of one of the tools depends on the user based on criteria such as friendly user interface or languages available, because the aforementioned online tools present similar characteristics.

\section{REAL IMPLEMENTATION OF THE TRADITIONAL GAMES}

\subsection{Educational context}

The traditional games of hangman wordguessing and crossword have been used in the last 3 years in an Engineering Master Degree, specialized in Industrial Engineering and Logistics, more particularly in the subject of "Demand and Supply Management". The objective of this Master's Degree is to train professionals for companies who are able to analyze, model, design, implement and improve complex systems composed of people, materials, money, information, machines, technology and energy, in order to offer products and services in the shortest term and with the highest productivity, quality, reliability and efficiency. 
The Master's Degree lasts 3 semesters and it is equivalent to 90 European Credit Transfer and Accumulation System (ECTS) with the following distribution:

- Common subjects: 42 ECTS.

- Optional subjects: 36 ECTS.

- Master's thesis: 12 ECTS.

The subject, in which these traditional games have been applied, belongs to an optional block titled: "Procurement and Distribution" that consists of three subjects:

- Purchasing and Procurement (6 ECTS).

- Demand and Supply Management (6 ECTS).

- Transportation in Logistics (6 ECTS).

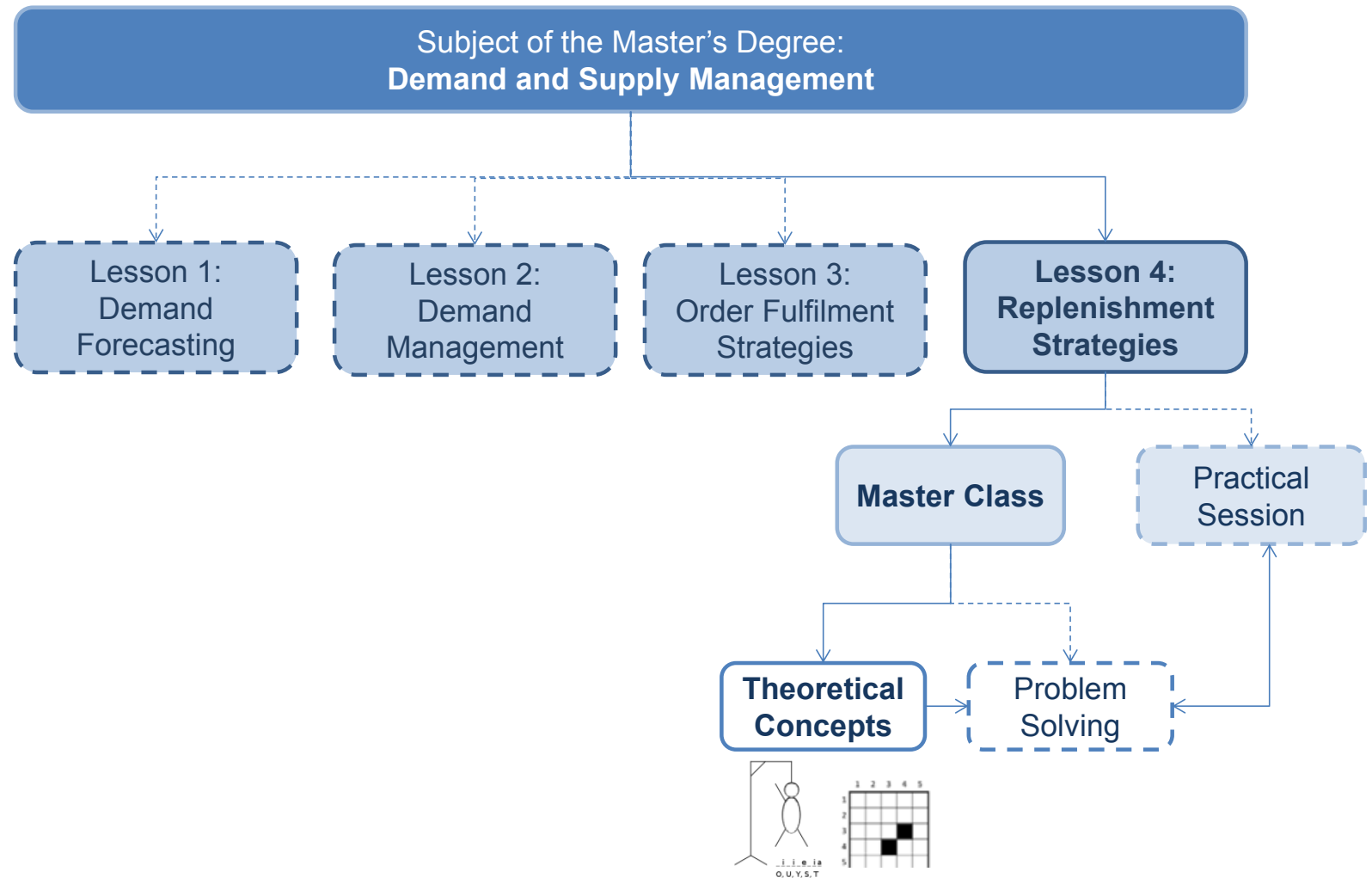

Figure 1. Conceptual and Organizational structure of the subject Demand and Supply Management.

The subject is the second one: "Demand and Supply Management". This subject is mainly divided into two parts. On one hand, the demand side that is in turn divided into two lessons: (1) Demand forecasting using techniques of time series and causal relationships forecasting and (2) Demand management through demand analysis and product segmentation techniques. On the other hand, the supply side is composed by two more lessons: (3) Order fulfilment strategies and (4) Replenishment systems and programmes. The lesson in which these traditional games have been applied is lesson (4). In this lesson, the students learn about the different replenishment strategies in order to determine the most efficient way to order inventory. The main strategies studied are Vendor Managed Inventory (VMI), Supplier Managed Inventory (SMI), Quick Response (QR), Continuous Replenishment Program (CRP) and Efficient Consumer Response (ECR). Moreover the lesson is structured, as it is shown in Figure 1, in master class and practical sessions (this last one are out of the scope of this paper). In the master class, first there are some sessions in which the different replenishment strategies are explained from a conceptual point of view to promote the creation of the knowledge base and theory building. And once that this phase has been achieved, the student has the capacities and skills to solve problems related to the comparison of costs between entities of the supply chain that are using traditional replenishment systems and those who collaborate through VMI. To reinforce the students' knowledge basis acquired during the master class and to facilitate the transition to the problem solving 
phase, some activities are performed to strength the theoretical concepts learnt and the traditional games are one of these activities.

\subsection{Examples of Both Games}

This section is mainly focused on showing an example of both games.

\subsubsection{Crossword}

The crossword has been created through the online resource: The TeacherCorner [7]. It is a simple crossword with only 9 words, but the crossword could be more complex with more words, with a maximum of 30 words that it is the limit that the online resource allows. Therefore, depending on the educational requirements the crossword could be more or less complex. As aforementioned in this paper it is only shown a small example which is illustrated in Figure 2. Below, the different definitions of the words (across and down) are shown:

\section{Across}

2. Replenishment systems must give an .... response to the customers.

4. The current replenishment systems are directed towards the ... so that business processes run together to reduce costs and

6. English acronym of code that enable the tracking of products in the supply chain.

7. The $20 \%$ of investments for the implementation of Continuous Replenishment Program (CRP) are aimed at ...

8. In Supplier Managed Inventory (SMI), the information provided by the manufacturer to the supplier is about ...

9. In Vendor Managed Inventory (VMI), the entity of the supply chain that has financial responsibility for the inventory is the ...

\section{Down}

1. Between the 80 's and 90 's, that Era was known as the 'Era of ... Management"

3. The Quick Response strategy minimizes the cost of ...

5. In Efficient Consumer Response (ECR), the manufacturer tries to adapt its production rate to the speed with which the product

Although the crossword was created through the online resource, the students do not use the online application to fill in the words but the empty crossword was printed and it was done to them in class.

\subsubsection{Hangman wordguessing}

The hangman game session consists of making game teams composed by three members and these game teams play randomly among them. In order words, team 1 plays against team 2, and they play one round (while the other teams are looking at the game performance). The winner is classified into the category $\mathrm{A}$, and this team will play again against another team in this category. The procedure is going on till only one team is the winner. During the session, all the teams are involved while its classmates are playing.

Figure 3 shows an example of the online tool "Ahorcado" [16], in which the player has to choose a letter from the alphabet that appears on the left. If the letter is part of the word, then it appears down. If the letter does not belong to the word, the game emits a sound and part of the body of the hangman is drawn. The game also offers a score depending on the length and complexity of the word and the number of tries that the player needs to guess the word. However, in the class session, the game is not based on this scoring, but it is only based on if the team wins or not. The difficulty of the words is one of the challenges of the game teams because the different teams have to define their own words. The more difficult the words defined by a group, the more complex the teams, the more difficult the words defined by a group, the more chances the team has to win. These words should be related to the lesson 4 of replenishment strategies. Another rule of this session is that a team could not use a word that has been already used in a previous game, in order to avoid repetitions. In this case, the game is performed through the online 'Ahorcado' tool. 

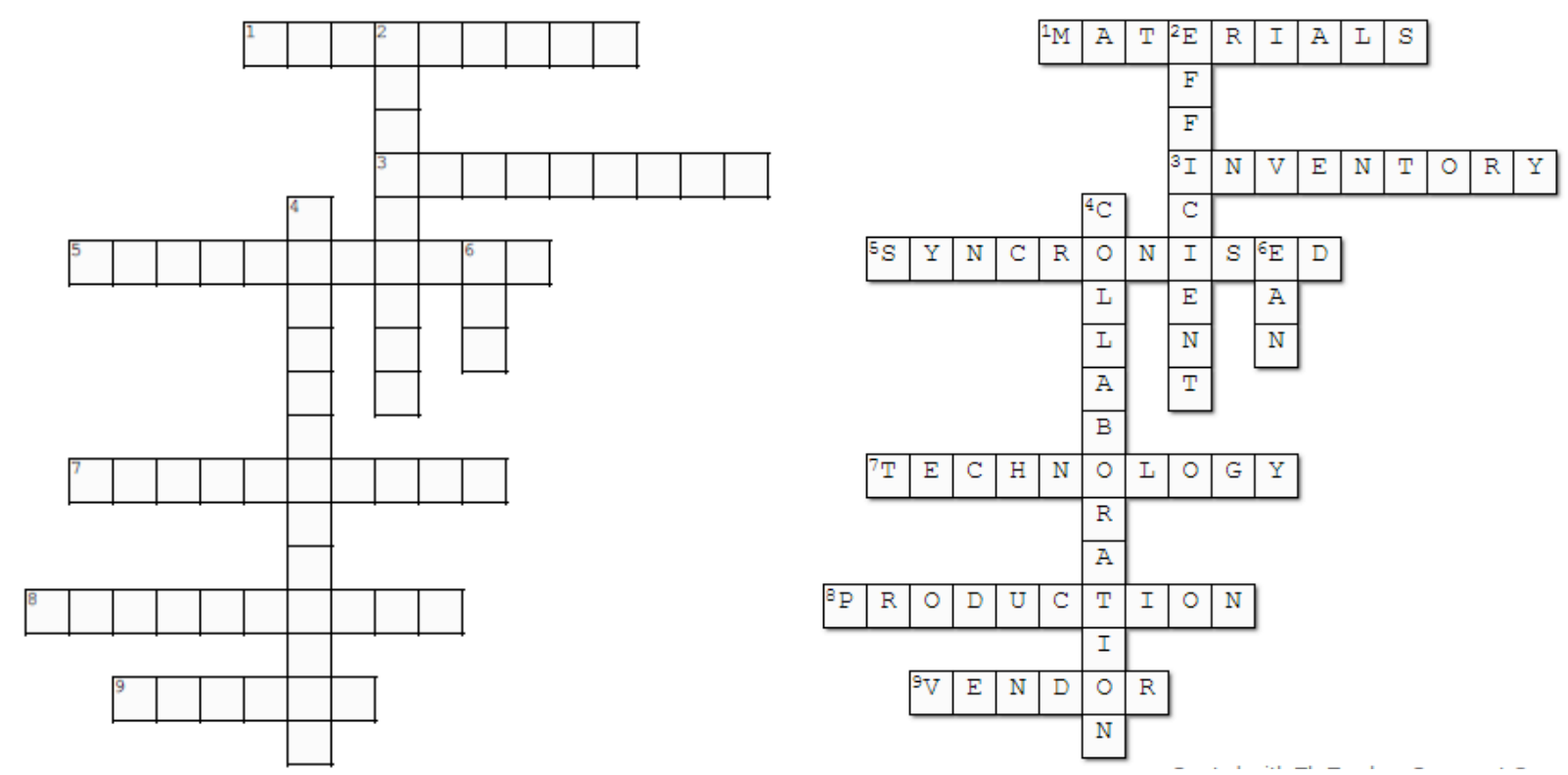

Figure 2. Structure of the empty crossword and its solution [7].
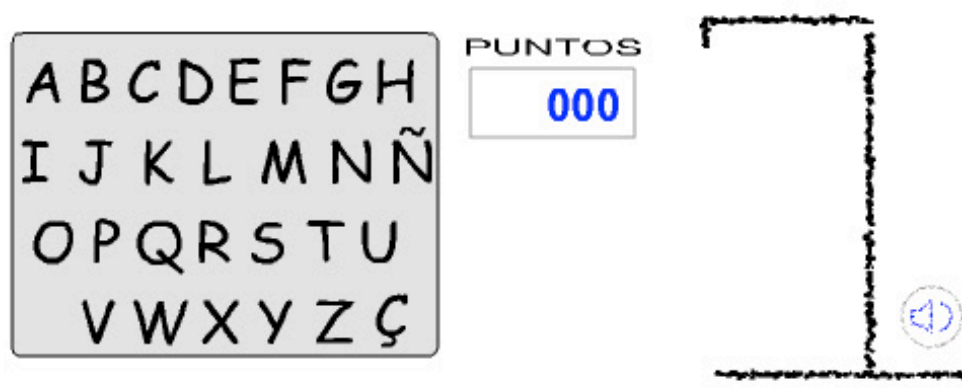

Figure 3. The hangman game interface of the online resources 'Ahorcado' [16].

\section{CONCLUSION}

The traditional games are an ideal way to learn while playing as they generate great satisfaction among the students. Based on the experience gained, through the use of these games in the context of a class in an Industrial Engineering Master Degree, we can conclude that these games create a kind environment to promote the competitiveness in the classroom, the self-assessment of the students and also reinforce the concepts already learnt in the master class.

The crossword game was configured with the support an online tool [7] available free which is very easy to use and offer the game in a printable version. It also offers the possibility to play online but in this case, the session was performed in an offline manner.

The hangman game is the classic game intended to help improve the player's vocabulary. In this case the objective was not exactly focused on the vocabulary but the main goal was that students were able to remember new concepts with which they were not familiar (replenishment strategies).

The students' opinion is that the crossword game was more difficult to solve than the hangman one. Although it is worth to mention that in the first case, the students were trying to solve the crossword game separately while the hangman game was performed by teams.

The improvement that these games have supposed to the knowledge reinforcement has not been assessed quantitatively; however the students assess this experience very positively. 


\section{REFERENCES}

[1] Shute, V. J., Rieber, L., \& Van Eck, R. (2011). Games... and... learning. Trends and issues in instructional design and technology, 3.

[2] Devries, David L.; Edwards, Keith J. Learning games and student teams: Their effects on classroom process. American Educational Research Journal, 1973, vol. 10, no 4, p. 307-318.

[3] Kiili, Kristian. Digital game-based learning: Towards an experiential gaming model. The Internet and higher education, 2005, vol. 8, no 1, p. 13-24.

[4] Csikszentmihalyi, M. (1991). Flow: The psychology of optimal experience. New York7 Harper Perennial.

[5] Webster, Jane; Trevino, Linda Klebe; Ryan, Lisa. The dimensionality and correlates of flow in human-computer interactions. Computers in human behavior, 1994, vol. 9, no 4, p. 411-426.

[6] Inbar, M., \& Stoll, C. S. (1970). Games and learning. Interchange, 1(2), 53-61.

[7] The Teacher Corner. (2017). [Online]. Available: https://worksheets.theteacherscorner.net/make-your-own/crossword/lang-es/

[8] Instant Online Crossword Puzzle Maker. (2017). [Online]. Available: http://www.puzzlemaker.com/CW/

[9] Crossword Labs. (2017). [Online]. Available: https://crosswordlabs.com/

[10] Puzzle Maker. (2017). [Online]. Available: http://puzzlemaker.discoveryeducation.com/CrissCrossSetupForm.asp

[11] Teacher Stuff (2017). [Online]. Available: http://tools.atozteacherstuff.com/free-printablecrossword-puzzle-maker/

[12] Crossword Puzzles Games. (2017). [Online]. Available: http://www.crosswordpuzzlegames.com/create.html

[13] Ed Helper. (2017). [Online]. Available: http://edhelper.com/crossword.htm\#optionsan

[14] Eclipse Cross Word. (2017). [Online]. Available: http://www.eclipsecrossword.com/

[15] ProProfs Brain Games (2017). https://www.proprofs.com/games/word-games/hangman/create/

[16] Ahorcado (2017). http://www.ahorcado.net/condiciones.txt

[17] MyLanguageExchange. (2017) https://www.mylanguageexchange.com/HManBuilder.asp

[18] AHangman (2017). www.ahangman.com 